\title{
Assessment of Environmental Effects of Post-Blasted Explosive on the Ecosystem of Old Netim Village in Akamkpa Local Government Area of Cross River State, Nigeria
}

\author{
"ALABA, OC; ADEBAYO, B; ADESIDA, PA \\ Department of Mining Engineering, Federal University of Technology, Akure, Nigeria \\ *Crresponding E-mail: ocalaba@futa.edu.ng; badebayo@futa.edu.ng; paadesida@futa.edu.ng
}

\begin{abstract}
The study investigated the effects of post-blast explosive residues on ecosystems around Prodeco Quarry industry in Calabar Nigeria by collecting explosives residues and air/fumes samples. The variation between the intensity and temperature of explosive dissolution in the mine environment shows that TNT appears at the lowest temperature of $10^{\circ} \mathrm{C}$ and PETN reflected at about $35^{\circ} \mathrm{C}$ and NG shows almost at $58^{\circ} \mathrm{C}$. Consequently, $5-15 \mathrm{~kg}$ of ANFO produced 10-30 lit/kg of nitrogen oxide compound (NOx) fumes while $20 \mathrm{~kg}$ ANFO produced $40 \mathrm{lit} / \mathrm{kg}$ of carbon monoxide fume. Also, $0.2 \mu \mathrm{g} / \mathrm{L}$ concentration of explosive in water recorded the highest mean recovery of $116.0 \%$ while $1.0 \mu \mathrm{g} / \mathrm{L}$ recorded the highest values of $99.0 \%$. The mean recovery in soil sample is range between $105.0-126.0 \%$ while that of forest is range between $91.0-107.0 \%$ with the $50.0 \mu \mathrm{g} / \mathrm{L}$ concentration of explosive. The study concluded that the contaminating effects of the explosives residues have direct and indirect influences on the growth and development of the ecosystems.
\end{abstract}

\section{DOI: https://dx.doi.org/10.4314/jasem.v22i5.22}

Copyright: Copyright $\odot 2018$ Alaba et al. This is an open access article distributed under the Creative Commons Attribution License (CCL), which permits unrestricted use, distribution, and reproduction in any medium, provided the original work is properly cited.

Dates: Received: 03 April 2018; Revised: 23 April: 2018; Accepted: 26 April 2018

Keywords: explosive, blasting materials, ecosystems, quarry

The applications of explosive in exploration and exploitation of mineral through blasting operations have greatly contributed to the development of the utilization of numerous mineral resources. On the other hand, the fumes and others residues of the blasted explosives have caused a lot of biodegradation and hazardous impacts on ecosystem survival in a quarry environment (Juhasz and Naidu, 2007)). Srivastava and Vellend (2005) defined ecosystems as the network of interactions between organisms and their environment, which can be of any size but usually encompass specific, limited spaces. Meanwhile, Erick et al. (2013) described explosive as materials which are in a metastable state and are capable of undergoing a rapid chemical reaction without the participation of external reactants such as atmospheric oxygen. Katarzyna et al. (2013) established the use of explosives in large scale by both the military and industries such as mining industries, high-energy metalwork industries, munitions manufacturing industries and civil engineering industries which have resulted in high levels of ecosystem contamination. According to Maurie and Priyadarshi (2011), the most relevance field of applications of explosives among others is in the mining through blasting operations in both surface and underground mining activities. The surface mining applications of explosives include quarrying and open pit mineral extraction for the production of granite aggregates, stone base and asphalt used in construction of building, bridges and roads; limestone, marble, shale for cement factories; metal productions coppers, gold, iron ore for steel companies (Meyer et al. 2007). Meanwhile, the underground mining applications of explosives include coal production, metal production, uranium and radioactive metals (Cooper, 1996). Explosives are made up of either a pure chemical compound or a mixture of several chemical compounds that react violently and vigorously to produce explosion spontaneously or on initiation (Porterfield, 1993; Akhavan, 2011). Harold and Douglas (2009) and PerAders Persson et al., (2009) classified explosives based on their physical/chemical properties as: gelatin explosive (dynamites, barbarite and boosters); powder explosive (ammonite, methanite, carbonites charge for splitting rock and ANFO) and emulsion explosive (bulk emulsion explosive and cartridge emulsion explosives). According to Winfield et al (2004) there has been presence of 2,4,6-trinitrotoluene (TNT), hexahydro-1,3,5-trinitro-1,3,5-triazine (RDX, hexogen) and octahydro-1,3,5,7-tetranitro-1,3,5,7tetrazocine (HMX, Octogen) in soil, surface water and groundwater where these explosives are being used. Most of the blasted explosives are stable in soil due to their chemical structures and easily binding to the soil organic matter, which making soil remediation 
difficult (Rylottet al, 2011). Also, the high concentration of Trinitrotoluene, Hexogen and Octogen have resulted to decrease in terrestrial plant biomass, abnormality growth in terrestrial plants and decrease in biomass and fertility of earthworm (Best et al., 2006, Rocheleauet al., 2008, Winfieledet al., 2004; Vila et al., 2007, Lachanceet al., 2004, Krishnan et al., 2000). Domestic consumption of explosives and blasting agents during the year 2002 was about 5.53 billion pounds (USGS, 2003). Out of this, about 3.79 billion pounds $(68.5 \%)$ were used in coal mining, 1.17 billion pounds $(21.1 \%)$ in metal and nonmetal mining, and 417 million pounds $(7.5 \%)$ in construction blasting (USGS, 2003). As a result of the frequent uses of explosive and explosive materials in Prodeco Quarry, this study, thereby assess environmental effects of post-blasted explosive on the ecosystem of Old Netim Village in Akamkpa Local Government Area of Cross River state, Nigeria.

\section{MATERIALS AND METHODS}

Description of the Study Area: Prodeco Nig. Ltd is located at Old Netim Village in Akamkpa Local Government Area of Cross River state between latitude 5033'0'N to 6054'0'N and longitude 8018 '0'E to 8039 '30'E. The quarry site is located adjacent to thick forest and surrounded with water where both terrestrial and aquatic habitats reside. The quarry is near a community that their major occupation is farming. The major operation of the company is quarrying of granite deposit for construction purposes which include drilling and blasting using explosive and explosive materials for rock fragmentation and crushing of the blasted rock into aggregate uses for construction purposes.

Explosive Residues Samples: The explosives residue samples were collected by swabbing the surface of the post-blast debris and skin with wet cotton ball. The cotton balls were wet as already been soaked in 0.50 $\mathrm{mL}$ (50:50 water: methanol). The samples collected by cotton swabs were kept inside polythene bag for laboratory analyses. In the laboratory, the captured explosives were extracted from the cotton ball into water. The cotton ball was placed at the bottom of a 10 -mL plastic syringe; drawn $10 \mathrm{~mL}$ of water into the syringe, the syringe was allowed to stand for 15 minutes before releasing the water from the syringe into a collection tube. Then Solid Phase Extraction (SPE) was applied to the $10-\mathrm{mL}$ extract to isolate the organic explosives. A 3-mL, Waters Oasis Sorbent, SPE tube was conditioned, loaded with extract, washed, and explosives escaped with methanol, followed by direct analysis of the resulting extract solution using high-performance liquid chromatography (HPLC) with ultraviolet (UV) detector. Analysis was performed on an octadecylsilane-based (C18) column using acetonitrile-water mixture $(55: 45)$ as mobile phase in accordance with Umi et al. (2008). The mobile phase was pumped at $1.0 \mathrm{~mL} / \mathrm{min}$ and separation affected using an isocratic mode with the detection wavelength of $230 \mathrm{~nm}$. The procedure was repeated with various volumes of extract using larger sizes of plastic syringe $20 \mathrm{~mL}, 30 \mathrm{~mL}, 40 \mathrm{~mL}, 50 \mathrm{~mL}, 60 \mathrm{~mL}, 70 \mathrm{~mL}, 80 \mathrm{~mL}$, $90 \mathrm{~mL}, 100 \mathrm{~mL}$ and different concentration results of explosives (PETN) contents in water were obtained and recorded.

Water Samples: Water samples were collected from open pit mines sump, surface (hole) reservoir and nearby river to the blasting site. The water was sampled with washed and rinsed plastic containers in accordance with APHA (1998) standard methods before taken to laboratory for analysis. The $100 \mathrm{~mL}$ water samples were passing through a solid phase extraction (SPE) cartridge containing $500 \mathrm{mg}$ of a divinylbenzene/vinylpyrrolidone copolymer and a 47 $\mathrm{mm}$ disk containing a reverse phase sulfonated polystyrene divinylbenzene phase in accordance to EPA 3535A standard method to detect the explosive and extracted. $4 \mathrm{ml}$ of acetonitrile was used to elect extracted components of the sulfonated polystyrene divinylbenzene phase cartridge, followed by final dilution to exactly $5 \mathrm{ml}$ with acetonitrile. A white precipitate formed by mixing the diluted extract was removed with a $0.45 \mu \mathrm{m}$ polytetrafluorethylene (PTFE) syringe filter. The sample components were separated, identified, and measured by injecting an aliquot of the concentrated extract into a high resolution fused silica capillary column of a GC/MS system with a programmed temperature vaporizing (PTV) injector. Compounds eluting from the GC column were identified by comparing their measured mass spectra and retention times to reference spectra and retention times in a database. Analysis was performed using full scan and selected ion monitoring (SIM) mass spectrometry. Reference spectra and retention times for analyses were obtained by the measurement of calibration standards under the same conditions used for samples. The concentration of each identified component was measured by relating the MS response of the quantization ion(s) produced by that compound to the MS response of the quantization ion(s) produced by a compound that is used as an internal standard. The mean recovery from seven replicate $500 \mathrm{~mL}$ water samples extracted using solid phase extraction cartridge and with a final volume of $5 \mathrm{~mL}$ of acetonitrile was recorded. 
Air Samples: Air samples were collected from the blasting chamber. A total volume of blasting chamber of $79.236 \mathrm{ft}^{3}\left(25.56 \mathrm{~m}^{3}\right)$ was created in the mineral ore body (granite) at the Prodeco quarry, enclosed between two explosion proof bulkheads. The collection of the fumes was carried out by detonating explosive (primer) with blasting agent and confining the fumes. Following the shot, a fan mounted at one end of the chamber mixes the chamber atmosphere at $3,500 \mathrm{ft} 3 / \mathrm{min}$. The samples were taken to laboratory for analyses. The fumes collected were analyzed using bubblers or vacutainers to collect samples for analysis at the analytical chemistry lab according to Mine Safety and Health Administration (MSHA) and International Makers of explosives in Pittsburgh Research Center's Experimental Mine. Measurements and test analyses of fumes produced by blasts enable the determination of fumes that were produced. The procedure was repeated with different quantity of ammonia nitrate fuel oil (ANFO) and the following fume production results were recorded.

Soil Samples: Soil samples were collected from nearby forest around the quarry locations and other samples were collected around the blasting phase of the company. The soil samples were collected between the depths of $0-15 \mathrm{~cm}$ with an auger and kept in a well labeled air tight polythene bag before transfer to the laboratory for analysis. A quantity of $1000 \mathrm{~g}$ was taken from each soil sample and mixed with methanolacetonitrile; shake for about 5 minutes using mechanical shaker, followed by extraction in an ultrasonic bath with the use of acetonitrile. The separation of explosives in liquid extracted samples was conducted with the use of Thermo Scientific, Hypersil Gold C18 $250 \times 4.6 \mathrm{~mm}$ chromatography column (filling granulation $-5 \mu \mathrm{m}$ ) proceeded with precolumn Hypersil Gold $10 \times 4 \mathrm{~mm}$ (filling granulation $-5 \mu \mathrm{m}$ ). The detection of explosives was done by the method of high performance liquid chromatography. The procedure was repeated for different quantities of the various soil samples collected at mine and forest sites $2000 \mathrm{~g}, 3000 \mathrm{~g}, 4000$ g, 5000 g, 6000 g, 7000 g. Explosives concentrations in the soil sample were measured in accordance with EPA Method 8095. The explosives contamination (accumulation) was measured in each soil sample and recorded.

\section{RESULTS AND DISCUSSION}

Explosive Residue: Figure 1 shows that high accumulation of explosive residue in a blasting environment yield increase in concentration of contaminating the lives of terrestrial and aquatic habitats living in the immediate surroundings of the blasting area. The graph shows that concentration is directly and indirectly increasing as the volume of the analyte increases. Meaning that there is tendency of high adverse effects on the natural organic matters as the increase in volume is proportional to increase in concentration.

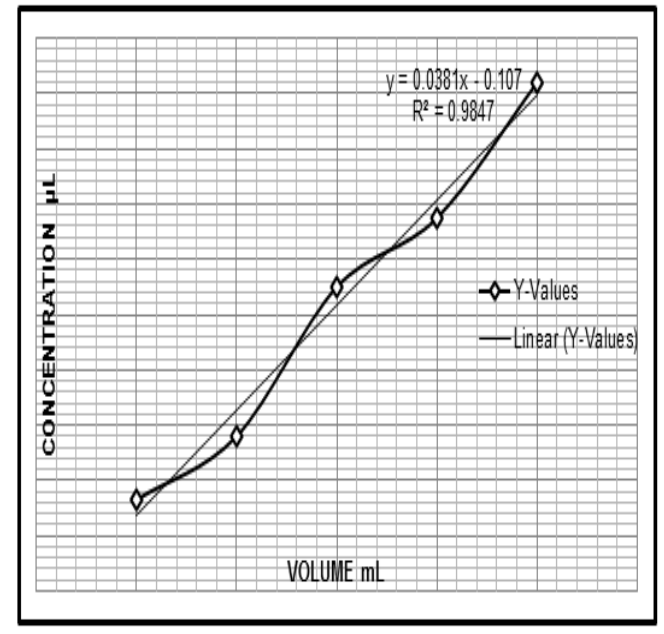

Fig 1: Concentrations versus volumes of explosive residue

Figure 2 shows the variation between the intensity and temperature of explosive dissolution in the mine environment. It was discovered that explosive contents were identified separately by the intensity of individual components as they appeared at different temperatures and compared to limit detection table whereby different explosive components signified at different temperature, such that TNT appears at the lowest temperature of approximately $10^{\circ} \mathrm{C}$ and PETN reflected at about $35^{\circ} \mathrm{C}$ and $\mathrm{NG}$ shows almost at $58^{\circ} \mathrm{C}$. Thus, explosive dissolution from the solid residue occurs in stages with temperature changes; thereby determines the level of contaminations in the blasting environment (topsoil and water) based on temperature difference. This implies that the potential for high intensity increases with increase in temperature which enhanced life deteriorations and gaseous emissions to the mine's environment. Moreso, Figure 3 shows that the intensity of analyte increases with time. This means that time (frequency) is the important factor that determines explosive impacts on the mine's environment. As often as the residue is produced from holes charging and deflagration results, as much as contamination of the environment grows consequentially and diminishes as long as soil consumed the chemical components.

Air Sample: Figures 4 shows the levels of toxic fume produced with the quantity of the explosive detonated. The generation of the fume depends on the quantity of explosives and blasting agent being used. The graph shows that when $2 \mathrm{~kg}$ of ammonia nitrate fuel oil 
(ANFO) was used no fume was detected, but when 5 - $15 \mathrm{~kg}$ of ANFO was used, nitrogen oxide compound (NOx) was the major fume detected while carbon monoxide was the fume detected when above $15 \mathrm{~kg}$ of explosive was used. This revealed that the more the quantity of explosive used, the more poison fume produced. The nitrogen oxide compound and carbon monoxide released to the atmosphere from blast explosives contaminate both the ecosystems and the environment due to their poisonous nature. The long time exposure to these gases caused the various health hazards for ecosystem and quarry workers witness with the environment.

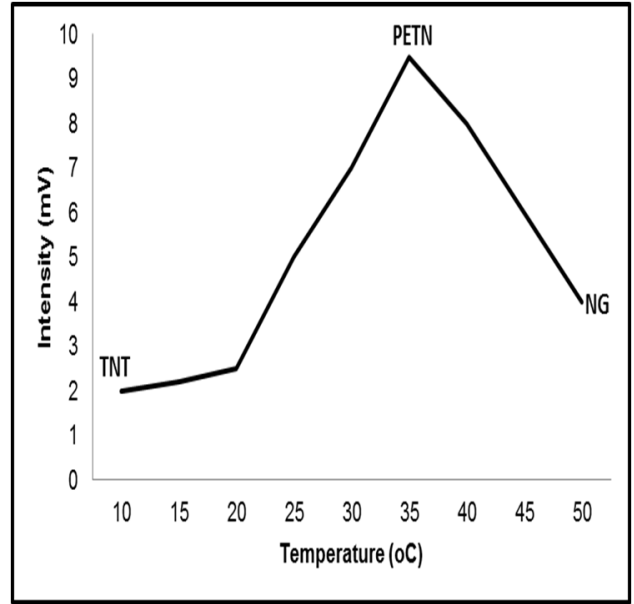

Fig 2: Variation of intensity versus temperature

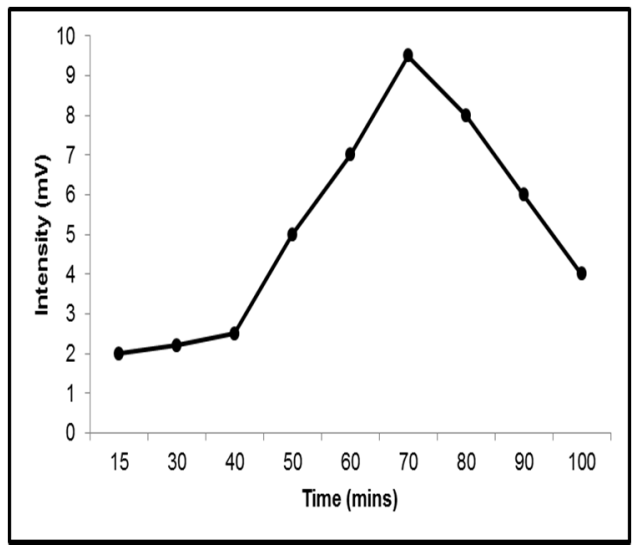

Fig 3: Variation of intensity versus time

Also, Figure 5 shows the quantity of fuel oil being used when mixing ANFO. The higher the fuel quantity the higher the fumes produce and the higher its environmental contamination. The predominant fume that is normally produced when using higher fuel is carbon monoxide which is dangerous to both man and animal within the blasting environment. Other fumes that are produced are also dangerous as well despite the little quantity, but can easily be transformed to higher useful compounds.

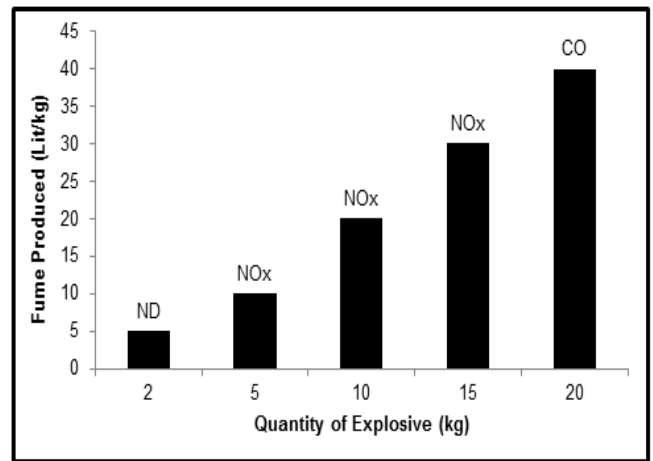

Fig 4: Quantity of fume produced with ANFO

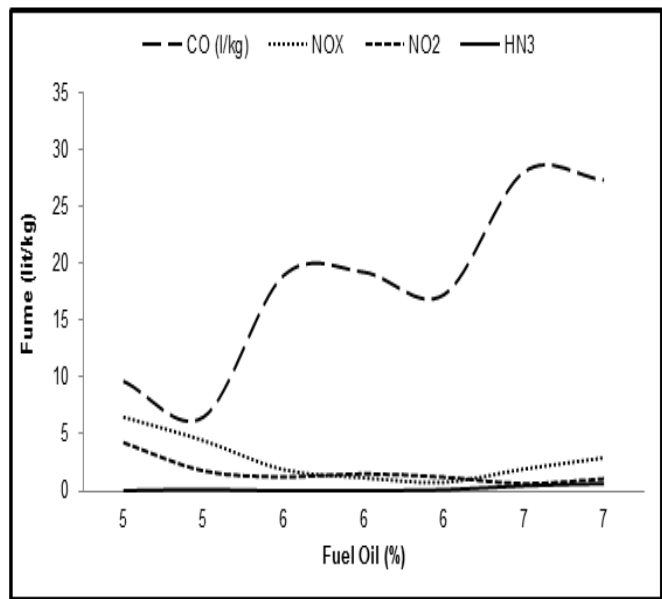

Fig 5: Quantity of Fumes produced with Fuel Oil

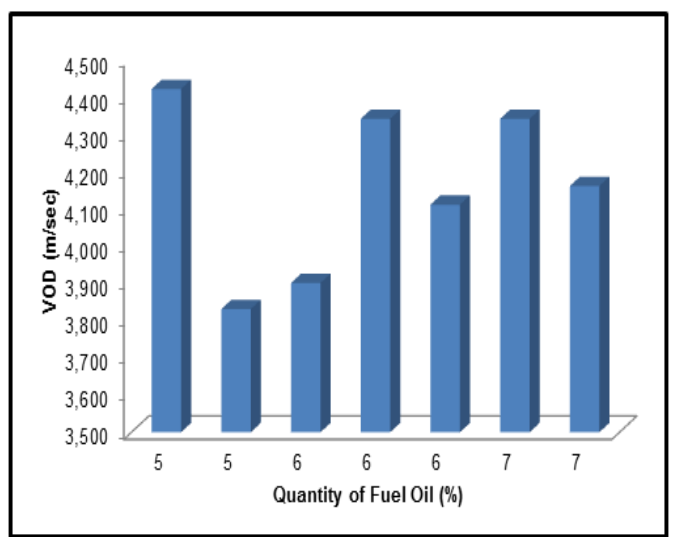

Fig 6: Quantity of Fuel Oil versus VOD

However, Figure 6 shows that variations of fuel oil affect velocity of detonation (VOD) which implies that low VOD results in fume production and in turns yield contamination of the environment.

Water Samples: Figure 7 shows that water samples have different explosive concentrations that caused environmental contaminations to both aquatic and terrestrial habitats. The heighes mean recovery was recorded at $116.0 \%$ when the concentration of explosive is $0.2 \mu \mathrm{g} / \mathrm{L}$ while $99.0 \%$ was recorded 
when the explosive concentration is $1.0 \mu \mathrm{g} / \mathrm{L}$. This implies that explosives contamination of water has toxic effect on the ecology and man who depend on the water source for survival. The ionic products of explosives that reacted with the water rendered the water toxic to health, and corrosive to the mining equipment while the purification expenditure of this contaminated water usually results to loss in mine economics. The infiltration and percolation process of water from the surface to the depth usually carries a trace ionic quantity of explosives to underground that influences the taste of underground water within the study area.

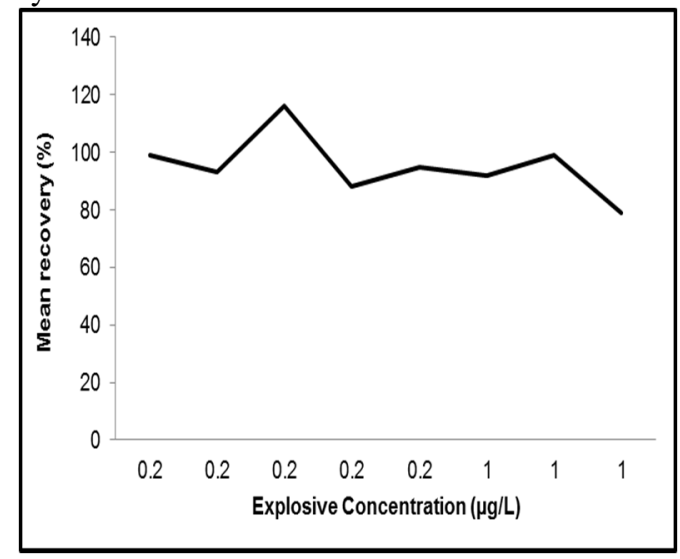

Fig 7: Mean recovery in water versus explosive concentration

Soil Samples: Figure 8 illustrates that concentration of explosive contents in blasting site is very high as a result of immediate deposition of blast explosive residues causing cascading, karsts and geomorphic generation from repeated explosive chemical reactions that alter material properties of soil and rocks within the quarry environment. Consequently, there was increased in explosive contamination within the blasting area until a stage whereby the residual accumulation was spread to immediate environments through erosion and denudation and diminishing in concentration was manifested.

Figure 9 shows continuous spreading of explosives residues and their variable concentration changes in the nearby forest. Consequently, the effect of explosives contamination on wildlife, microorganisms, plants, man and vegetation was manifested from growth and development retardation and hazardous health conditions due to their interrelated and interdependent in food chain and food web within an ecosystem or habitat. Figure 10 compares the mean recovery which shows higher distribution of explosive in blasting site than in the forest simply because of repeated explosion and direct residual deposition on the blasting site immediate environment; whereas the forest is indirectly contaminated through agents of erosion and denudation (wind, water, waves and gravity) with limited and uneven distribution of residual explosives. This has an impact on the natural habitat of living organisms within the reach of the explosives at the blasting site more than in the forest.

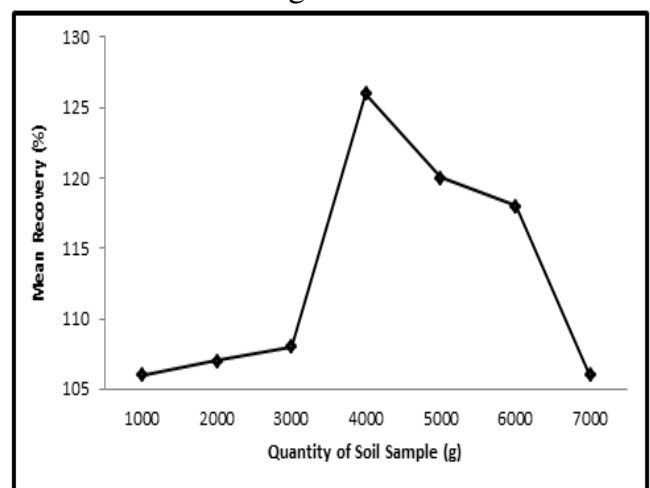

Figure 8: Mean recovery versus soil quantity in blasting site

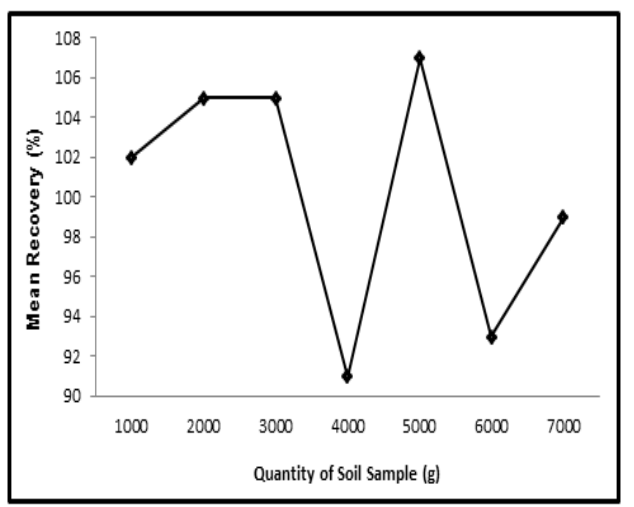

Fig 9: Mean recovery versus soil quantity in forest

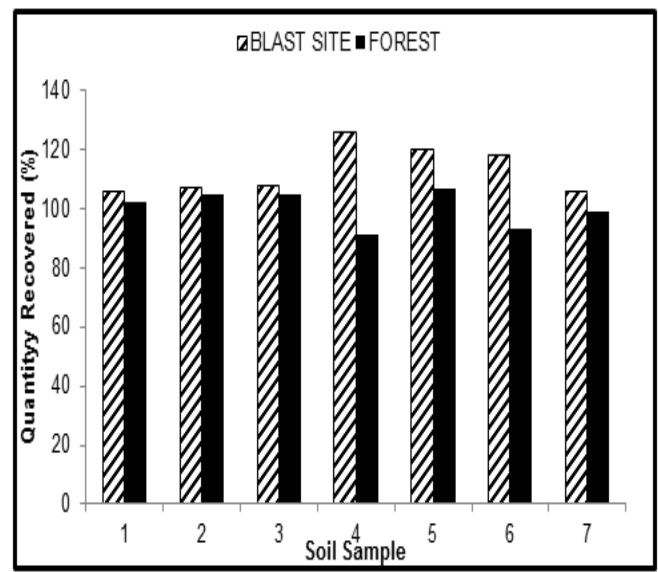

Fig 10: Comparison of soil and forest samples recovery

Conclusion: The contamination from blast explosives residues in quarry operations go beyond visible assessment as usually insinuated by the miners but it requires scientific and technological detection. The analyses demonstrated have confirmed the presence of explosives residues; carbon monoxide, nitrogen 
oxides, dust, smoke, undetonated and deflagrated explosive compounds as contaminants in quarry and its environments. The contaminant effects of the explosives residues have their direct and indirect influences on the growth and development of the ecosystems, the biodegradation, geomorphic, cascading, karsts and other topographic deformations which affect the quarry environments landslide and inhabitants. The direct contamination effects of residual explosive on living inhabitants of an ecosystem include eye irritation, health deterioration, air, water and land pollutions, and the indirect influences are on inanimate living creatures upon which man and animal depend. The plants and vegetation that are responsible for photosynthesis and oxygen production are suffering undergrowth and development which in return have effects on animate creatures that depend upon them. The study therefore suggested that quarry operators should ensure appropriate and proper selection, application and detonation of explosives during quarry operations. The proper selections of explosive usage will enhance total detonation and prevent deflagration which might yield residue generation while proper application will protect wastage that accumulate as contaminants which might hinder soil fertilities and fuel generation through chemical reactions that kill bio-organisms like bacteria, fungi, algae and others.

\section{REFERENCES}

Akhavan, J (2011). The chemistry of explosives, Third Edit. Norfolk: Biddles Ltd., Kings Lynn, Norfolk.

Best, EPH., Geter, KN., Tatem, HE and Lane, BK (2006). Effects, transfer, and fate of RDX from aged soil in plants and worms. Chemosphere, 62:616-625

Cooper, P (1996). Explosives engineering. Wiley-VCH, Inc. United States of America.

EPA Method 3535A: Solid-Phase Extraction (SPE). EPA site.

EPA Method 8095: Explosives by Gas Chromatography. EPA site.

Harold, DM and Douglas, KW (2009). A Guide to the safe storage of explosive materials. Occupational Safety and Health Division, NCDOL, Raleigh.

Juhasz, AL and Naidu, R (2007). Explosives: fate, dynamics, and ecological impact in terrestrial and marine environments. Rev Environ Contam Toxicol, 191:163215
Katarzyna, P., Korneliusz, M and Tadeusz, S (2013). Synergetic toxic effect of an explosive material mixture in soil. Bulletin of Environmental Contamination and Toxicology, 91(5):555-559

Krishnan, G., Horst, GL, Shea PJ (2000). Differential tolerance of cool- and warm-season grasses to TNTcontaminated soil. Int J Phytoremediation, 2:369382

Lachance, B., Renoux, AY., Sarrazin, M., Hawari, J and Sunahara, GI (2004). Toxicity and bioaccumulation of reduced TNT metabolites in the earthworm Eisenia andrei exposed to amended forest soil. Chemosphere, 55:1339-1348

Maurie, P and Priyadarshi, H (2011). Blasting - Technology solutions for mining. TechnoMine.

Meyer R, Köhler J, Homburg A (2007). Explosives, 6th, Compl. Weinheim: Wiley-VCH Verlag $\mathrm{GmbH}$, Weinheim.

Porterfield, WW (1993). Inorganic chemistry of explosive: A unified approach, 2nd ed., Academic Press, Inc., San Diego, pp. 479-480

Rocheleau, S., Lachance, B., Kuperman, RG., Hawari, J., Thiboutot, S., Ampleman, G., Rylott, EL., Lorenz, A and Bruce, NC (2011). Biodegradation and biotransformation of explosives. Curr Opin Biotechnol, $22: 434-440$

Srivastava, DS and Vellend, M (2005). Biodiervsityecosystem function research: is it relevant to conservation? Annual review of Ecology, Evolution and Systematics, 36:267-294.

Sunahara, GI (2008). Toxicity and uptake of cyclic nitramine explosives in rye-grass Lolium perenne. Environ Pollut, 156:199-206

Umi, KA., Sumathy, R and Syahidah, AH (2008). Forensic analysis of explosive residues from hand swabs. The Malaysian Journal of Analytical Sciences, 12(1):25-31.

USGS (2003). Minerals Information. Explosive Web

Vila, M., Lorber-Pascal, S and Laurent, F (2007). Fate of RDX and TNT in agronomic plants. Environ Pollut 148:148-154

Winfield, LE., Rodgers, JH and D'Surney, SJ (2004). The responses of selected terrestrial plants to short $(<12$ days) and long term (2, 4 and 6 weeks) hexahydro1,3,5-trinitro-1,3,5-triazine (RDX) exposure Part I: growth and developmental effects. Ecotoxicol, 13:335347 